\title{
Практика отбора инвестиционных проектов для целей бюджетного финансирования
}

\author{
Савин С.Ю. ${ }^{8}$
}

В последнее время широкое распространение получили электронные программы по составлению бизнес-планов, которые позволяют сравнивать бизнес-плань между собой путем сопоставления финансовых показателей таких проектов. Однако такая возможность сравнения очень условна и относительна.

Бизнес-план - это продукт индивидуального творчества, отражающий интеллектуальный уровень, опыт и знания частного инвестора в определенной области экономической детальности. Это также промежуточный документ, отражающий частный взгляд инвестора на экономическую ситуацию вокруг инвестиционного проекта с позищий сегодняинего дня.

При распределении бюджетных ресурсов на иели поддержки инвестииионных проектов органы государственного управления в приоритетном порядке решают задачи реализация определенных направлений стратегий экономического развития, перевода экономики на современные стандарты в области технологий, энергосбережения $u$ соблюдения норм охраны окружающей среды. Соответственно показатели финансовой эффективности частного проекта носят в этом случае скорее справочный, чем определяюший, характер. С этих позищий представляются спорныли встречающиеся в российских нормативных документах указания о том, что показатели финансовой эффективности инвестиционного проекта являются наиболее значимыми при конкурсном отборе таких проектов при предоставлении финансовой поддержки.

$$
\text { JEL: H810, O220 }
$$

Ключевые слова: бизнес-план, эффективность проекта, распределение бюджетных ресурсов

При всем многообразии субъектов и объектов инвестиционной деятельности можно выделить два основных, которые выступают движущей силой инвестиционных процессов, это инвестор и его бизнес-план. Вложение инвестором средств в объекты инвестирования с целью получения прибыли неразрывно связано с проведением мероприятий по бизнеспланированию. В свою очередь бизнес-планирование возникает постольку, поскольку инвестор намерен осуществить инвестиции. Такая взаимосвязь определяется сущностью инвестиций. Дж. М. Кейнс определял инвестиции как «часть дохода за данный период, которая не была использована на потребление», и как «текущий прирост ценности капитального имущества в результате производственной деятельности данного периода» [Keynes, 1936]. В этом определении объединены две основополагающие стороны категории инвестиции - аккумулирование ресурсов с целью накопления дохода и использование ресурсов с целью прироста капитального имущества. Иными словами, «инвестиции» - это осознанный отказ от текущего потребления в пользу возможного относительно большого дохода в будущем, который, как ожидается, обеспечит и большее суммарное потребление. Инвестиции вкладываются на краткосрочной или долгосрочной основе в экономику страны или за ее территориальными пределами и сопровождаются постоянным контролем уровня прироста ресурсов в результате такой инвестиционной деятельности.

Начало любого бизнес-процесса связано с первоначальным инвестированием ресурсов.

\footnotetext{
${ }^{8}$ Канд. эконом. наук, доцент кафедры экономики и финансов фирмы факультета экономики Национального исследовательского университета «Высшей школы экономики».
} 
В процессе инвестиционной деятельности инвестор постоянно сталкивается с риском неполучения ожидаемого дохода или экономического эффекта либо полной или частичной утраты вложенных инвестиций. Одним из методов управления инвестиционными рисками выступает мониторинг двух важнейших составляющих инвестиционного процесса стоимости ресурсов, аккумулированных для получения дохода в будущем, и показателей прироста получаемого дохода.

В природе не существует гарантированного метода получения дохода на вложенный капитал. Каждый инвестиционный проект уникален; как следствие, не существует двух повторяющихся во всех деталях проектов. Внешняя экономическая ситуация, в которой реализуется проект, всегда уникальна. Так же уникальны внутренние параметры инвестиционного проекта, в том числе цена на используемые инвестиционные ресурсы, уровень производственных издержек, сам объект, на котором ведется предпринимательская деятельность, управленческие решения по реализации проекта, а участники проекта всегда по-разному оценивают риски, связанные с реализацией проекта.

Бизнес-план выступает документом, в котором инвестору представляется возможность дать полное описание особенностей своего инвестиционного проекта, микро- и макроэкономических факторов, влияющих на его реализацию, сформулировать свои подходы к оценке инвестиционных рисков, оценить эти риски, сделать прогноз развития рыночной ситуации в краткосрочной, среднесрочной и долгосрочной перспективе вокруг инвестиционного проекта, спрогнозировать свои действия по реализации проекта.

Определение бизнес-плана можно найти в российском законодательстве. Согласно закону «Об инвестиционной деятельности в Российской Федерации, осуществляемой в форме капитальных вложений», определение бизнес-плана дается в контексте инвестиционного проекта, осуществляемого в форме капитальных вложений: «инвестиционный проект - обоснование экономической целесообразности, объема и сроков осуществления капитальных вложений, в том числе необходимая проектная документация, разработанная в соответствии с законодательством Российской Федерации и утвержденными в установленном порядке стандартами (нормами и правилами), а также описание практических действий по осуществлению инвестиций (бизнес-план)» ${ }^{9}$. В этом определении бизнес-план представлен как обоснование и описание комплекса практических взаимосвязанных действий по осуществлению инвестиций. Подразумевается, что техникоэкономическое обоснование (ТЭО) инвестиционного проекта выступает технологической платформой бизнес-плана. Соответственно в сравнении с ТЭО бизнес-план подробно излагает и обосновывает политику инвестора по обеспечению успеха его будущей продукции или услуг на рынке, в том числе тактику и стратегию продвижения продукции или услуг на рынок, ценовую и конкурентную политику.

Таким образом, бизнес-план описывает цели и задачи, которые должны быть решены в процессе инвестиционной деятельности; способы достижения поставленных целей; техникоэкономические и финансовые показатели проекта; оценку текущей рыночной ситуации, складывающейся вокруг проекта. В этом документе может рассматриваться эффективность проекта для всех заинтересованных сторон, с учетом различных приоритетов и интересов участников проекта. Особое внимание должно уделяться мероприятиям по снижению риска, а также гарантиям возврата вложенных средств инвесторам.

Бизнес-план призван продемонстрировать сильные и слабые стороны инвестиционного проекта, качество и глубину проработки концепции ведения бизнеса. Этот интеллектуальный продукт отражает уровень знаний и опыта предпринимателя в области финансового менеджмента, в том числе в области организации предпринимательской деятельности, юриспруденции, налогового, бухгалтерского и финансового учета, маркетинга, анализа и прогнозирования хозяйственной деятельности.

Учитывая сложность процессов разработки бизнес-плана, международное деловое

\footnotetext{
9 Федеральный закон от 25.02.1999 «39-Ф3 «Об инвестиционной деятельности в Российской Федерации, осуществляемой в форме капитальных вложений», ст. 1.
} 
сообщество сформулировало ряд основополагающих принципов и стандартов, которые лежат в основе подготовки бизнес-плана. Например, такие стандарты применительно к инвестиционным проектам в области промышленного производства разработаны Комитетом по промышленному развитию при ОOH (UNIDO). Согласно подходу ЮНИДО, единый принцип при составлении бизнес-плана состоит в том, что в целях снижения инвестиционных рисков и обеспечения успеха каждый инвестиционный проект должен быть всесторонне изучен, обоснован, оценен и разработан план реализации инвестиционного проекта. В 1981 году UNIDO разработала программу «Computer Model for Feasibility Analysis and Reporting» (COMFAR), которая используется в настоящее время в 160 странах мира как стандартный подход к подготовке бизнес-плана инвестиционного проекта в сфере промышленности. Первые версии программы COMFAR позволяли проводить исключительно оценку финансового состояния предприятия и новых инвестиционных проектов в сфере промышленности. Современные версии программы COMFAR включают в себя уже такие функции, как одновременная рейтинговая оценка до пяти инвестиционных проектов, а также оценка влияния на инвестиционный проект соблюдения норм и требований по охране окружающей среды.

Программа COMFAR ознаменовала новый уровень в использовании электронных таблиц и шаблонов для систематизации имеющейся у инвестора информации для описания его бизнес-идеи. На российском рынке появились программные продукты, позволяющие с учетом особенностей российской договорно-правовой системы формализовать бизнес-идеи, предполагаемые к реализации на российской территории. К числу таких программ относятся, в частности такие программы по составлению бизнес-плана, как Business Plan PL, Project Expert и «Альт-Инвест». В этих программах бизнес-план представлен как документ, в котором излагаются:

1. Характеристика инвестиционного проекта, его основные участники, характеристика отрасли, в которой предполагается реализация проекта, производственного, организационного и маркетингового планов.

2. Обобщение основных финансово-экономических характеристик инвестиционного проекта, таких как:

- характеристика текущего состояния компании согласно балансовой и управленческой отчетности;

- характеристика требуемых инвестиций;

- характеристика производственно-сбытовой деятельности;

- источники и условия финансирования проекта;

- принципы распределения доходов (выплаты из прибыли, дивиденды);

- прогноз экономического окружения (инфляция, налоги, курсы валют).

3. Построение модели инвестиционного проекта и проведение финансового анализа этой модели.

Каждая из таких программ генерирует обязательный набор показателей экономической эффективности инвестиционного проекта, в том числе показатели внутренней нормы доходности (IRR), чистого дисконтированного дохода (NPV) и индекса прибыльности (PI). C учетом такого содержания такие программы фактически предлагают пользователям детальное технико-экономическое и финансовое обоснование эффективности рассматриваемых действий по вложению инвестиционных ресурсов, т.е. детальный инвестиционный анализ. Именно такой продукт и получают пользователи программ по составлению бизнес-планов. Российские программы, в силу того что в них используются возможности электронных таблиц, по определению могут генерировать только часть бизнесплана в виде инвестиционного анализа. Такая особенность российских программ по составлению бизнес-планов, как правило, не афишируется. И многие инвесторы попадаются в эту ловушку.

Не являются исключением и органы государственного управления, в практике деятельности которых бизнес-план инвестиционного проекта также используется как 
инструмент при распределении средств государственного бюджета. Для этих целей на законодательном уровне разработаны и приняты шаблоны и методики оценки бизнес-плана. Например, Постановлением Правительства РФ от 22.11 .1997 № 1470 «Об утверждении Порядка предоставления государственных гарантий на конкурсной основе за счет средств Бюджета развития РФ и Положения об оценке эффективности инвестиционных проектов при размещении на конкурсной основе централизованных инвестиционных ресурсов Бюджета развития РФ» установлена структура и шаблон подготовки бизнес-плана. В бизнес-плане должна присутствовать, в частности, следующая информация:

- название организационно-правовой формы предприятия;

- объем кредита;

- целевое назначение кредита;

- возможная эффективность использования заемных средств;

- целесообразность привлечения кредита;

- порядок погашения задолженности.

- резюме инвестиционного проекта с информацией об инвесторе, сути проекта, структуре финансирования, основных финансовых показателях проекта, и заявлением о коммерческой тайне;

- анализ положения дел в отрасли;

- описание производственного плана с обоснованием выбора производственного процесса и характеристикой технико-экономических показателей согласно проектносметной документации;

- план маркетинга с обоснованием затрат на сбыт продукции и отсутствием серьезных проблем со сбытом такой продукции;

- организационный план;

- финансовый план.

Согласно установленным нормам, финансовый план рассматривается как «ключевой» раздел бизнес-плана, в силу того что здесь излагаются планы затрат на реализацию проекта и показатели эффективности проекта, что косвенно закрепляет приоритет такого раздела бизнес-плана над другими разделами.

На практике это означает, что результаты проведенного финансового анализа инвестиционного проекта являются достаточными для сравнения инвестиционных проектов при распределении бюджетных ресурсов. Возникает вопрос, насколько обоснованным является подход к распределению бюджетных средств по результатам сравнительного анализа бизнес-планов, а точнее - представленных в них показателей эффективности инвестиционных проектов, подготовленных различными частными предпринимателями.

На первый взгляд, чем упрощенней подход к содержанию бизнес-плана, когда все сводится к набору определенных финансовых показателей, тем более объективен подход к оценке эффективности различных бизнес-моделей на основе представленных бизнес-планов. Однако ошибочность такого подхода состоит в том, что вряд ли возможно сравнивать результаты интеллектуального творчества конкретных предпринимателей, которые в силу собственного опыта и уровня знаний представляют прогнозы будущего в конкретно взятой области экономической детальности и затем формализуют их в виде шаблонов с показателями эффективности будущей инвестиционной деятельности.

При этом сами показатели эффективности инвестиционного проекта, излагаемые в результатах инвестиционного анализа, между собой несравнимы в силу множественности субъективных оценок и предположений, закладываемых в основу таких финансовых расчетов. Несопоставимость результатов инвестиционного анализа вытекает, в частности, из следующих соображений. Каждый инвестор индивидуально определяет свои риски ведения бизнеса, по-разному оценивает ситуацию в отрасли. Это тот субъективный фактор, который скрывается за формально объективными показателями эффективности будущей инвестиционной детальности.

Бизнес-план инвестиционного проекта в каждый отдельно взятый отрезок времени 
является промежуточным документом, который отражает субъективную оценку конкретным инвестором складывающейся экономической ситуации вокруг конкретного инвестиционного проекта. Поэтому ловкий инвестор может умело использовать бизнес-план, составленный формально (в строгом соответствии с предложенными шаблонами и системой показателей), против добросовестного конкурента, который подходит к оценке бизнес-плана с учетом максимально возможного учета рисков и наиболее консервативного подхода к оценке возможных изменений рыночной ситуации.

Бизнес-план неразрывно связан с инвестиционным проектом и всегда отражает частный интерес инвестора. Конкретный бизнес-план - это частный взгляд инвестора на ситуацию на рынке в отдельной сфере экономической деятельности. Поэтому формализованный подход к оценке бизнес-плана инвестиционного проекта (согласно унифицированным шаблонам и показателям) не менее опасен, чем отсутствие бизнес-плана. Важно иметь в виду, что при всем значении абсолютных и относительных показателей оценки эффективности инвестиционного проекта ни одни из этих показателей не является однозначным и абсолютным мерилом его эффективности и, соответственно, не может использоваться на государственном уровне как критерий выбора того, какой инвестиционный проект следует поддержать, а какому отказать в государственной поддержке.

Бизнес-план по определению не может считаться раз и навсегда законченным документом. Сделанные в бизнес-плане оценки, допущения подвергаются постоянным изменениям, которые предполагают внесение постоянных корректировок и изменений в него. В противном случае этот документ становится музейным экспонатом, не имеющий связи с реальной ситуацией на рынке. Бизнес-план устаревает, как только в нем ставится последняя точка, поскольку невозможно с точностью предвидеть, что произойдет на рынке завтра и в ближайшем или отдаленном будущем.

Для целей государственного регулирования функция бизнес-плана инвестиционного проекта, состоящая в том, что этот документ раскрывает концепцию, стратегию и тактику ведения бизнеса, представляется наиболее существенной и достаточной. На государственном уровне решаются задачи не обеспечения достижения максимальной нормы или массы прибыли в конкретной области предпринимательской деятельности, a реализации определенных направлений стратегии экономического развития. Соответственно, показатели экономической эффективности проекта, изложенные в бизнес плане конкретного предпринимателя, никак не могут выступать наиболее значимыми при распределении бюджетных средств на государственном уровне. Кроме этого, при распределении бюджетных ресурсов на цели поддержки инвестиционных проектов органы государственного управления должны руководствоваться соответствием таких проектов мировым стандартам в области технологий, энергосбережения и соблюдения норм охраны окружающей среды. Соответственно, именно эти разделы должны иметь приоритетный характер в представляемых частными предпринимателями бизнес-планах, а не показатели финансовой эффективности инвестиционной деятельности.

\section{Список литературы}

1. Федеральный закон РФ «Об инвестиционной деятельности в Российской Федерации, осуществляемой в форме капитальных вложений» № 39-Ф3 от 25.02.1999 (с дополнениями и изменениями).

2. Постановление Правительства РФ от 22.11.1997 N 1470 «Об утверждении Порядка предоставления государственных гарантий на конкурсной основе за счет средств Бюджета развития РФ и Положения об оценке эффективности инвестиционных проектов при размещении на конкурсной основе централизованных инвестиционных ресурсов Бюджета развития РФ».

3. Инвестиции: Учебное пособие / Г.П. Подшиваленко, Н.И. Лахметкина, М.И. Макарова 
и др. М.: КНОРУС, 2004.

4. Шарп У.Ф., Александер Г.Дж., Бейли Дж.В. Инвестиции. М.: ИНФРА-М, 1998.

5. Keynes, J. M. (1936), General Theory of Employment, Interest and Money. 